\title{
GLOBAL CaCO3 PRODUCTION BY REEF FORAMINIFERA
}

LANGER*, Martin R., Museum of Paleontology, University of California, Berkeley CA 94720; LIPPS, Jere H., Museum of Paleontology and Dept. of Integrative Biology, University of California, Berkeley, CA 94720; SILK, Michelle T., Dept. of Geology and Museum of Paleontology, Berkeley, CA 94720, U.S.A.

Global ocean calcium carbonate production has been estimated to be 5.3 billion tons/yr. Though reef complexes occupy less than one percent of the total oceanic area, approximately one fifth of the annual ocean carbonate production originates in shallow tropical reef environments. The high reef carbonate productivity is primarily benthic driven, often associated with algal symbiosis and exceeds planktic productivity by several orders of magnitude. Corals, calcareous algae and foraminifera account for the bulk of present-day reef carbonates. Although production and accumulation have been reasonably well constrained for some organisms, reliable carbonate production rates of reef foraminifera were known from only a few locations, precluding calculations at the global level.

We have calculated and compiled carbonate production rates of reef foraminifera from more than 50 localities spanning all major oceanic regions. Results from individual oceanic regions indicate average foraminiferal carbonate productivity rates of $81 \mathrm{~g} \mathrm{~m}^{-2} \mathrm{yr}^{-1}$ for the Asiatic, Indian, Red Sea, Persian Gulf, Carribean, North and South Pacific, and North and South Atlantic oceanic regions. Average productivity rates for individual regions, along with areal data derived from hypsometric charts, allowed us to calculate carbonate productivity for each oceanic province. Based on these data, we developed a software modelling program that calculates total foraminiferal carbonate productivity and accumulation for individual oceanic basins as well as globally. The program discriminates between productivity of symbiont- and non-symbiont-bearing organisms as well as areas of high and low productivity.

Computed totals show global carbonate production by reef foraminifera to be 50 million tons per year, of which approximately 40 million tons accumulate in reef sediments. The annual production of 50 million tons of reef foraminifera represents 1 percent of the present-day $\mathrm{CaCO}_{3}$ production in the world's oceans and approximately 5.6 percent of the global carbonate reef budget. Selected case studies indicate an average weight of $0.5 \mathrm{mg}$ per foraminiferal specimen, suggesting that each year approximately $100 \times 10^{15}$ foraminiferal individuals contribute to the global carbonate reef budget.

Reefal foraminiferal productivity in the Indian and the Asiatic regions alone exceeds 26 million tons per year, equaling nearly 55 percent of the foraminiferal carbonate production in shallow water reef environments. Forty million tons, roughly 80 percent of the total foraminiferal carbonate production are estimated to be produced by larger symbiont-bearing species alone. These production totals are likely to be conservative owing to the low values used for average productivity rates in individual oceanic regions. Despite the constraints imposed by applying low productivity averages, it is clear that foraminifera constitute a quantitatively significant component in the carbonate system of world reef environments. 